\title{
Sistem Pengontrol Suhu Ruangan Dengan Algoritma PID Menggunakan PLC OMRON CP1E-NA20DR-A
}

\author{
Wahyu Sapto Aji , Ade Junaidi \\ Program Studi Teknik Elektro, Fakultas Teknologi Industri, Universitas Ahmad Dahlan \\ Kampus III, JIn. Prof. Dr. Soepomo,S.H. Umbulharjo, Yogyakarta 551614 \\ e-mail: adejunaidistc@gmail.com
}

\begin{abstract}
Automatic control is developed in various fields including the application of temperature control systems in a plant. The application of industrial temperature control is found in industrial rooms such as cooling chambers, drying chambers, and oven chambers. However, it is necessary to have an automatic controller to monitor and regulate the ambient temperature conditions for the system to work properly. In this paper, we present the design of room temperature control using OMRON CP1E-NA2ODR-A PLC, incandescent lamp as a heat source, as well as LM35DZ sensor as the temperature sensor. This system uses PID Algorithm (Proportional, Integral, and Derivative) to make the control of the room temperature becomes faster and more precise. In addition, this prototipe provides two PID tuning options that are manual and auto tuning.
\end{abstract}

Keywords: temperature control; PID; PLC; LM35DZ; auto tuning

\section{Abstrak}

Pengendalian otomatis dikembangkan diberbagai bidang diantaranya adalah aplikasi sistem pengendalian temperatur pada suatu plant. Penerapan pengontrolan suhu pada industri banyak ditemukan pada ruangan industri seperti ruang pendingin, ruang pengeringan, dan ruang oven. Bagaimanapun, perlu adanya pengontrol otomatis untuk memantau dan mengatur kondisi suhu ruangan tersebut agar sistem dapat bekerja dengan baik. Pada paper ini, kami menyajikan perancangan kontrol suhu ruangan menggunakan PLC OMRON CP1E-NA20DR-A, lampu pijar sebagai sumber panas, serta sensor LM35DZ sebagai sensor pembaca suhu. Sistem ini menggunakan Algoritma PID (Proportional, Integral, and Derivative) agar pengontrolan suhu ruangan menjadi lebih cepat dan presisi. Selain itu purwarupa ini menyediakan dua pilihan penalaan PID yaitu manual dan autotuning.

Kata kunci: kontrol suhu; PID; PLC; LM35DZ; auto tuning

\section{Pendahuluan}

Perkembangan teknologi saat ini memegang peran penting dalam berbagai aspek tidak terkecuali di bidang teknologi otomasi yang terus mengalami perkembangan yang begitu pesat. Pengendalian otomatis sistem kendali atau sistem kontrol (control system) merupakan suatu sistem yang bertujuan untuk mengendalikan suatu proses agar keluaran yang dihasilkan dapat dikontrolkan sehingga tidak terjadi kesalahan terhadap referensi yang ditentukan [8]. Pengendalian otomatis banyak diterapkan diberbagai bidang diantaranya aplikasi pengontrol suhu di industri, suhu sendiri merupakan besaran fisis yang mengalir dari suhu yang lebih tinggi ke suhu yang lebih rendah [1].

Pada purwarupa ini akan menggunakan lampu pijar sebagai pemanasnya, pemanas akan hidup bila suhu ingin dinaikkan, dan pemanas dimatikan apabila suhu ingin diturunkan. Sebagai pendeteksi suhu, pada purwarupa ini akan memanfaat sensor suhu LM35DZ yang memiliki linieritas sebesar $10 \mathrm{mV} /{ }^{\circ} \mathrm{C}$ [2], hasil yang diharapkan adalah purwarupa ini akan mampu memberikan perintah atau pengendalian terhadap kondisi suhu pada ruangan tersebut. Purwarupa ini didesain agar dapat dimanfaatkan untuk keperluan lebih lanjut dalam pengontrolan suhu baik dalam ruangan maupun pada tempat-tempat khusus yang memerlukan pengendalian terhadap suhu. 


\section{Metode Penelitian}

Sistem pengontrol suhu ruangan pada penelitian ini menggunakan algoritma PID untuk melakukan pengolahan terhadap nilai masukkan, sistem pengontrol suhu dengan algoritma PID diterapkan pada PLC OMRON CP1E-NA20DR-A menggunakan fungsi PIDAT. Fungsi PIDAT adalah algoritma PID dengan autotuning yang sudah tersedia pada CX-Programmer [3] [4] [6] [7].

\subsection{Prinsip Kerja Sistem}

Pada dasarnya prinsip kerja sistem pengontrol suhu ini adalah dengan memanfaatkan logika PID untuk mengatur pemrograman pada PLC agar pengendalian suhu ruangan dapat dilakukan lebih optimal. Nilai set point dan juga umpan dari sensor akan di proses dengan algoritma PID yang kemudian hasilnya akan digunakan untuk mengatur plant pengontrolan suhu ruangan, gambaran prinsip kerja sistem dapat dilihat pada Gambar 1 berikut.

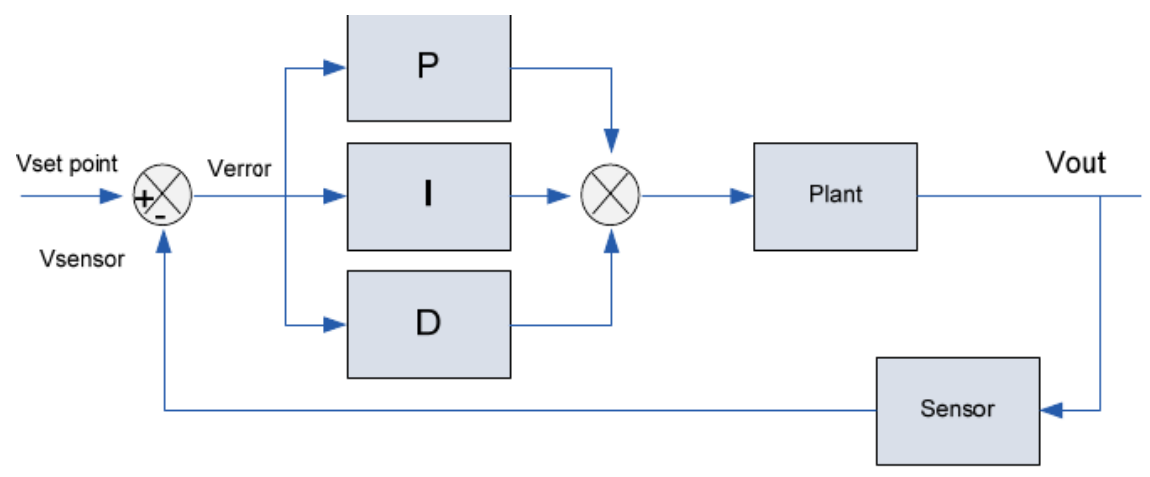

Gambar 1. Kendali PID pengontrol suhu ruangan

\subsection{Perancangan Perangkat Keras}

Perancangan perangkat keras terdiri dari 3 bagian utama yaitu sistem kontrol, sensor, dan perangkat sirkulasi udara. Sistem kontrol pada rancangan perangkat keras ini dilakukan oleh OMRON CP1E NA20DR-A untuk melakukan pengontrolan serta pengolahan data pada sensor, sedangkan sensor yang digunakan yaitu LM35DZ, Penggunaan lampu pijar (incandescent lamp) bertujuan untuk menggantikan sumber panas pada simulasi, sumber panas inilah yang kemudian dikontrol jika suhu ruangan mencapai batas nilai tertentu.

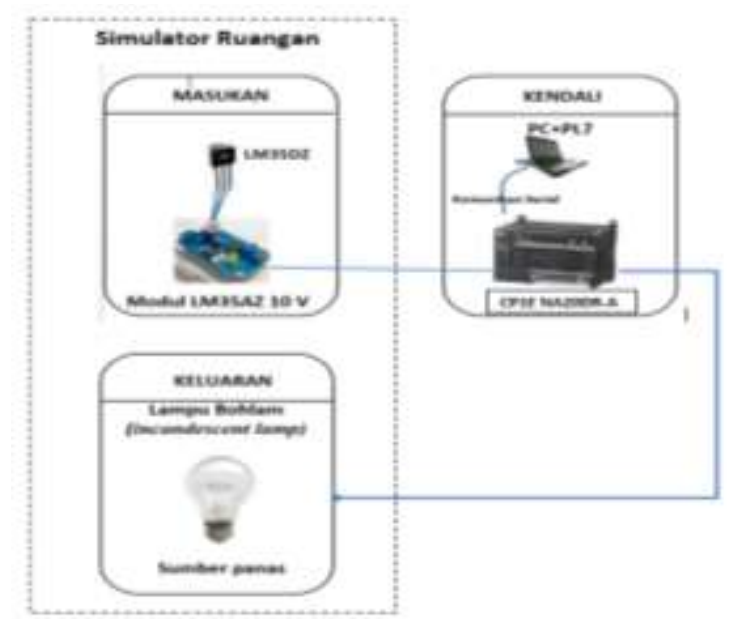

Gambar 2. Diagram blok rancangan perangkat keras

Keterangan diagram rancangan perangkat keras pada Gambar 2 terdiri dari 3 blok utama yaitu masukan yang teridiri dari modul LM35 untuk pembacaan suhu, blok kendali yang terdiri dari OMRON CP1E NA20DR-A sebagai pengontrol serta pengolah data, dan blok keluaran berupa lampu pijar (incandescent lamp) sebagai penghasil panas yang kemudian dikontrol untuk menjaga kondisi suhu yang ada pada simulator ruangan. 


\subsection{Perancangan Perangkat Lunak}

Perancangan perangkat lunak pada penelitian ini dibangun menggunakan perangkat lunak yang mendukung pemrograman OMRON CP1E NA20DR-A yaitu CX-ONE. Pada CX-ONE rancangan perangkat lunak akan dibangun sesuai dengan prinsip kerja yang ditunjukkan flowchart program pada Gambar 3.

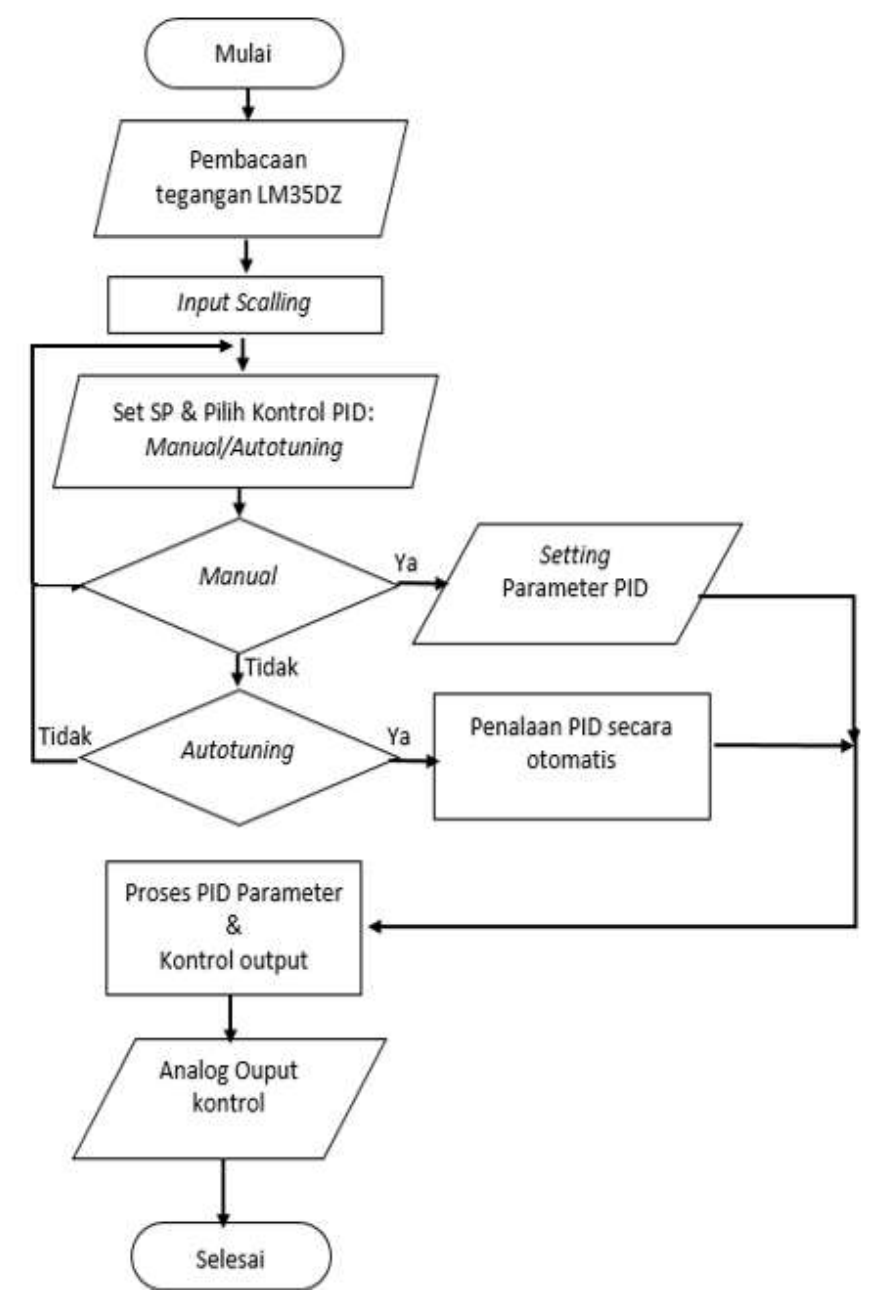

Gambar 3. Flowchart program pengontrolan suhu ruangan

Gambar 3 menjelaskan prinsip perangkat lunak diawali dari proses pembacaan tegangan pada sensor LM35DZ, setelah itu tegangan ini akan diolah untuk penskalaan ke celcius, nilai hasil penskalaan kemudian digunakan sebagai Process Variable (PV), selanjutnya menginputkan nilai Set Point (SP) yang menjadi acuan dalam pengontrolan suhu serta mode kontrol yang akan dilakukan pada sistem (Manual/Autotuning).

Mode manual mengharuskan pengaturan parameter secara manual, sedangkan autoning akan melakukan proses penentuan parameter secara terprogram, data tersebut akan diolah untuk mengontrol keluaran sistem, data keluaran tersebut akan dimanfaatkan oleh analog output untuk mengontrol suhu agar sesuai dengan set point yang telah dimasukkan.

\subsection{Pengujian Sistem}

Pengujian sistem meliputi pengujian perangkat keras dan juga perangkat lunak. Pengujian perangkat keras dimaksudkan untuk menguji perangkat keras yang digunakan meliputi pengujian sensor LM35DZ, serta integrasi dengan perangkat keras lainnya. Pengujian dimaksudkan untuk menguji perangkat lunak yang telah dibuat agar dapat terkoneksi dengan perangkat keras yang telah dibuat, dan dimaksukan untuk memastikan perangkat keras sudah bekerja sesuai dengan perancangan cara kerja alat yang dibuat. 


\section{Hasil dan Pembahasan}

Pada pembahasan ini akan menampilkan hasil pengujian terhadap perangkat keras dan perangkat keras serta pemdodelan sistem dengan menggunakan matlab.

\subsection{Pengujian Modul LM35AZ}

Modul LM35AZ merupakan modul yang dibangun dari sensor LM35AZ yang keluaranny a sudah dinaikkan menjadi 10 kali lipat dari tegangan aslinya, sehingga LM35DZ yang sebelumnya memiliki linearitas $10 \mathrm{mV} / \mathrm{C}^{\circ}$ maka pada modul LM35AZ akan berubah linearitasnya menjadi $100 \mathrm{mV} / \mathrm{C}^{\circ}$. Pengujian modul LM35AZ adalah dengan cara membandingkan perubahan nilai tegangan keluaran modul LM35AZ terhadap kenaikan suhu, dalam pengujian ini digunakan termometer digital sebagai pembanding. Grafik pengujian ditunjukkan pada Gambar 4.

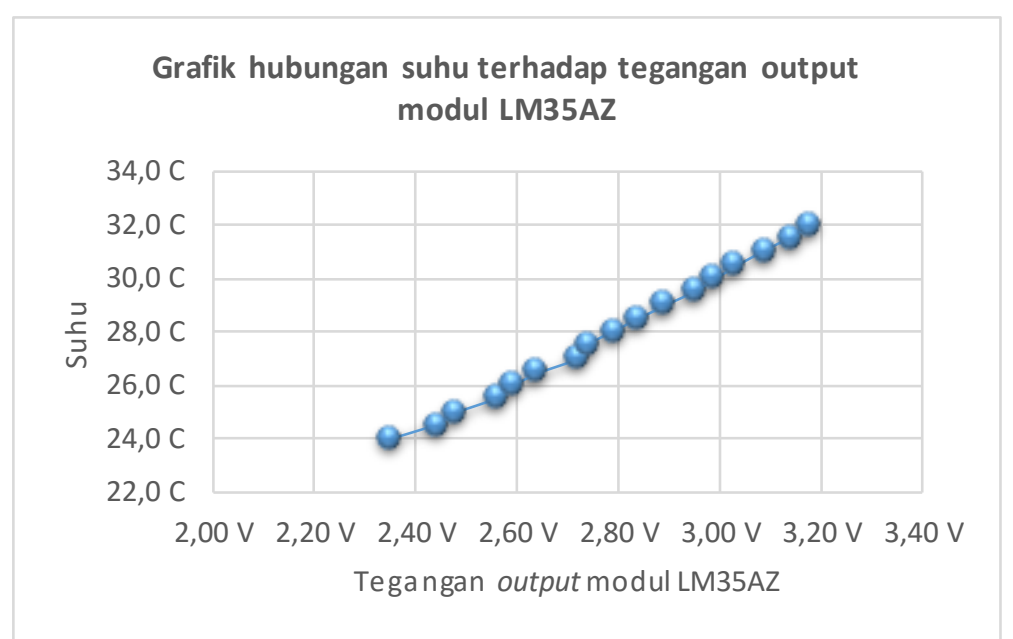

Gambar 4. Grafik hubungan suhu terhadap tegangan keluaran modul LM35AZ

\subsection{Pengujian Analog Input PLC}

Pengujian analog input pada PLC dilakukan untuk mengetahui apakah analog input pada PLC yang digunakan dapat berjalan dengan baik, dengan cara mengamati nilai masukkan yang terjadi pada PLC dengan menggunakan program CX-programmer, maka kondisi input analog dapat diketahui. Grafik pengujian ditunjukkan pada Gambar 5.

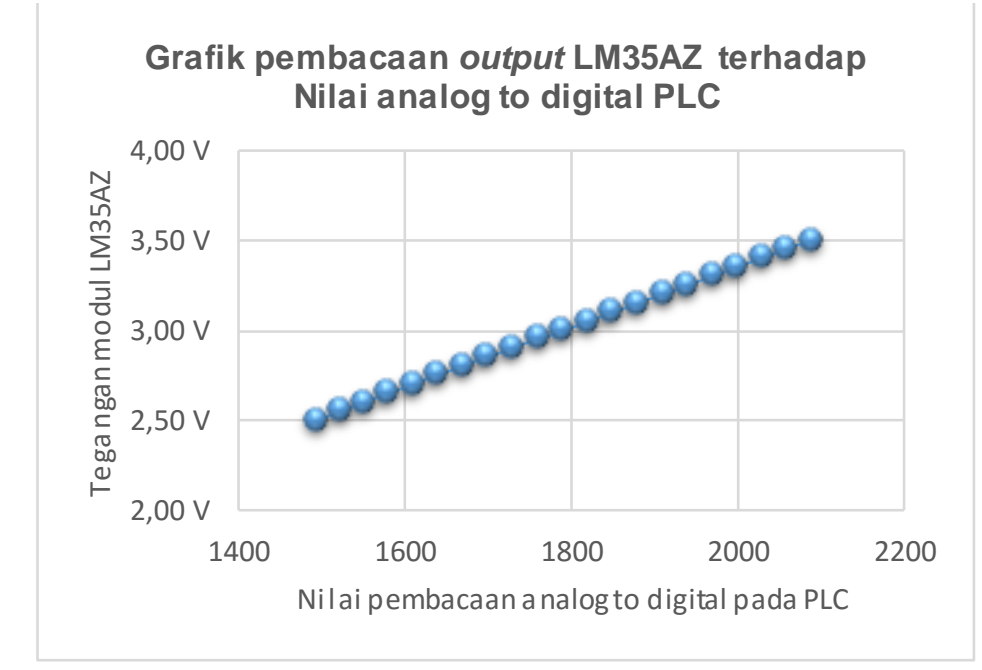

Gambar 5. Grafik hubungan keluaran modul LM35AZ terhadap input PLC

Pengambilan data Pengujian analog input pada PLC dilakukan dengan memberikan suhu tertentu pada LM35AZ, yang kemudian akan menghasilkan tegangan output, selanjutnya output diamati melalui pembacaan analog input PLC pada program CX-Programmer. 


\subsection{Pengujian Analog output PLC}

Pengujian analog output pada PLC dilakukan untuk mengetahui apakah analog output pada PLC berjalan dengan baik, dengan mengamati nilai keluaran yang terjadi pada PLC maka kondisi output analog dapat diketahui, berikut ini adalah data yang menunjukkan perubahan nilai keluaran pada PLC terhadap perubahan persentase pengaturan output PLC. Grafik pengujian ditunjukkan pada Gambar 6.

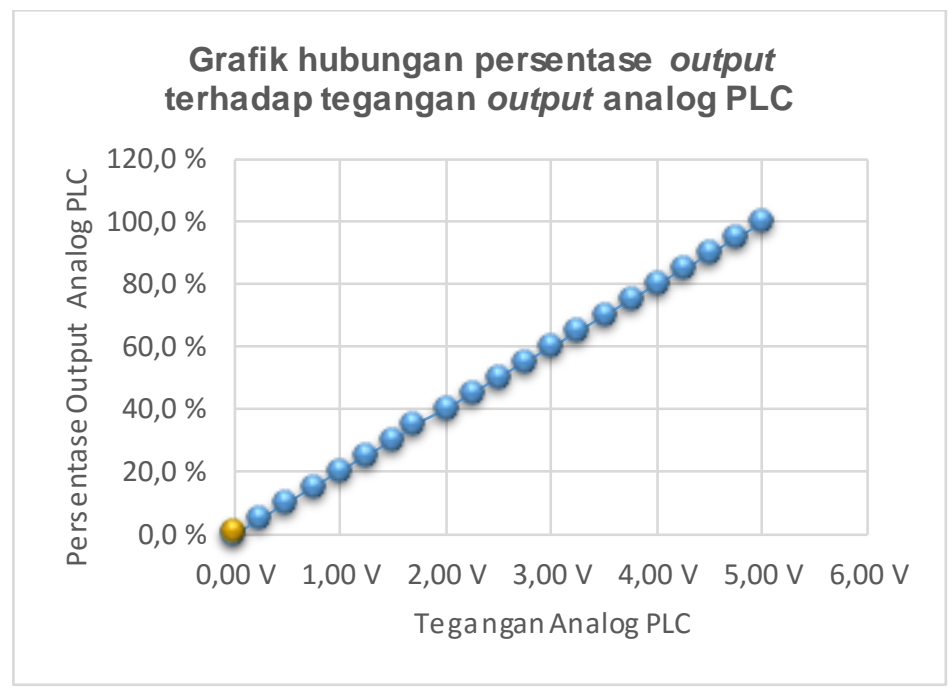

Gambar 6. Grafik hubungan persentase output terhadap tegangan output analog PLC

\subsection{Pengujian Solid State Relay (SSR)}

Pengujian Solid State Relay (SSR) dilakukan dengan cara memberikan range kerja tegangan yang berkisar antara OVDC-5VDC [5], sedangkan output diberi tegangan 240VAC, Pengujian ini bertujuan untuk mengetaui pengaruh nilai masukan padai Solid State Relay (SSR) terhadap tegangan keluarannya. Berikut ini adalah data yang menunjukkan perubahan tegangan input terhadap keluaran SSR. Grafik pengujian ditunjukkan pada Gambar 7.

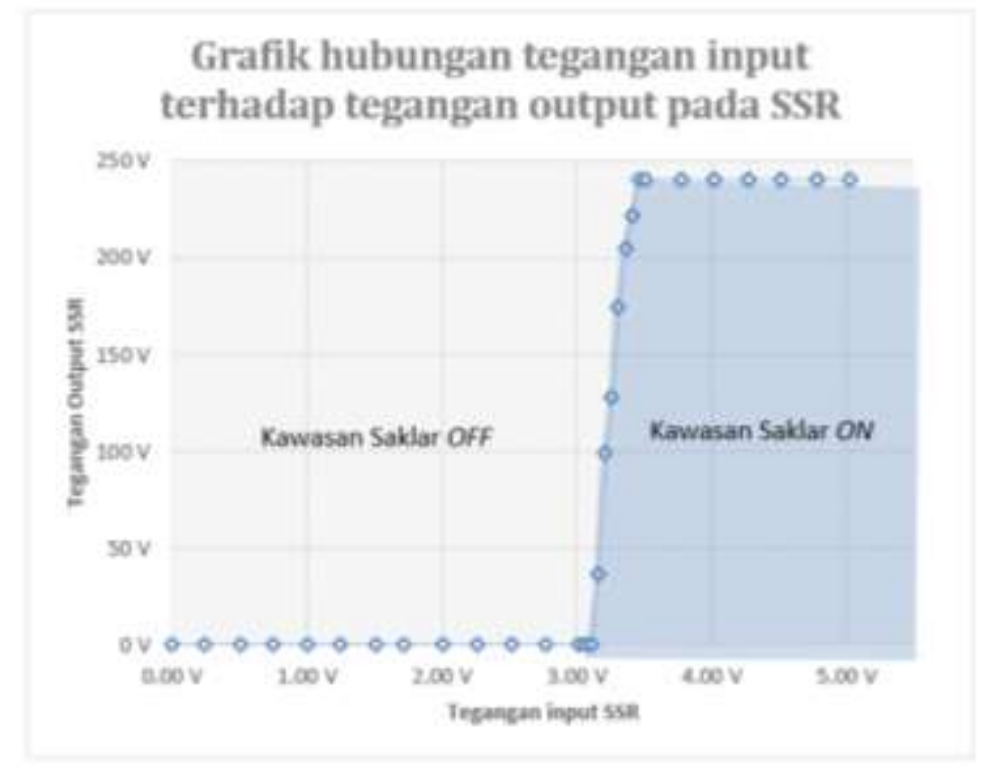

Gambar 7. Grafik hubungan tegangan input dan output pada SSR 
Berdasarkan data yang diperoleh, saklar pada SSR mulai menutup pada tegangan 3,16 $\mathrm{V}-3,46 \mathrm{~V}$ dengan output yang tidak stabil yang menyebabkan lampu pijar berkedip dan redup, pada tegangan 3,51 V saklar SSR menutup dengan sempurna dengan output 240 VAC.

\subsection{Pengujian Penalaan PID Secara Manual}

\subsubsection{Pengujian Kontrol $P I\left(K_{P}=10 \%, K_{I}=100\right)$}

Pengujian kontrol PI secara manual pada pengujian ini dilakukan dengan memberikan nilai $\mathrm{Kp}=10 \%$ dan nilai $\mathrm{K} \mathrm{I}=100$ serta nilai Set Point $(\mathrm{SP})=30.5^{\circ} \mathrm{C}$, berikut ini adalah Gambar 8 yang menunjukkan grafik kontrol PI.

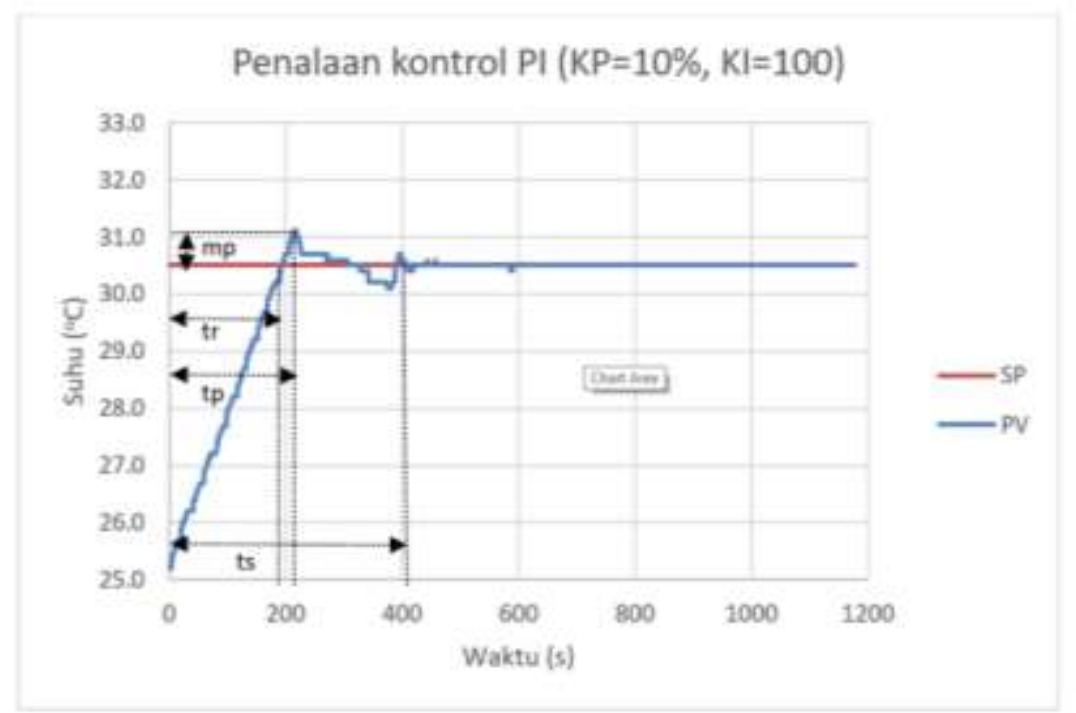

Gambar 8. Grafik penalaan manual PID $\left(\mathrm{Kp}=10 \%, \mathrm{~K}_{\mathrm{I}}=100\right)$

Penalaan PI secara manual pada pengujian ketiga menghasilkan tanggapan sistem dengan $\mathrm{tr}=193$ detik, waktu puncak (peak time) tp=214 detik, serta waktu tunak (settling time) ts $=405$ detik. Tanggapan sistem ini juga menghasilkan maximum over shoot (mp) sebesar 0.6 ${ }^{\circ} \mathrm{C}$ dari nilai set point (SP).

\subsubsection{Pengujian Kontrol PD $\left(K_{P}=10 \%, K_{D}=20\right)$}

Pengujian kontrol PD secara manual pada pengujian ini dilakukan dengan memberikan nilai $\mathrm{Kp}=10 \%$ dan nilai $\mathrm{KD}=20$ serta nilai Set Point $(\mathrm{SP})=30.5^{\circ} \mathrm{C}$, berikut ini adalah Gambar 9 yang menunjukkan grafik kontrol PD.

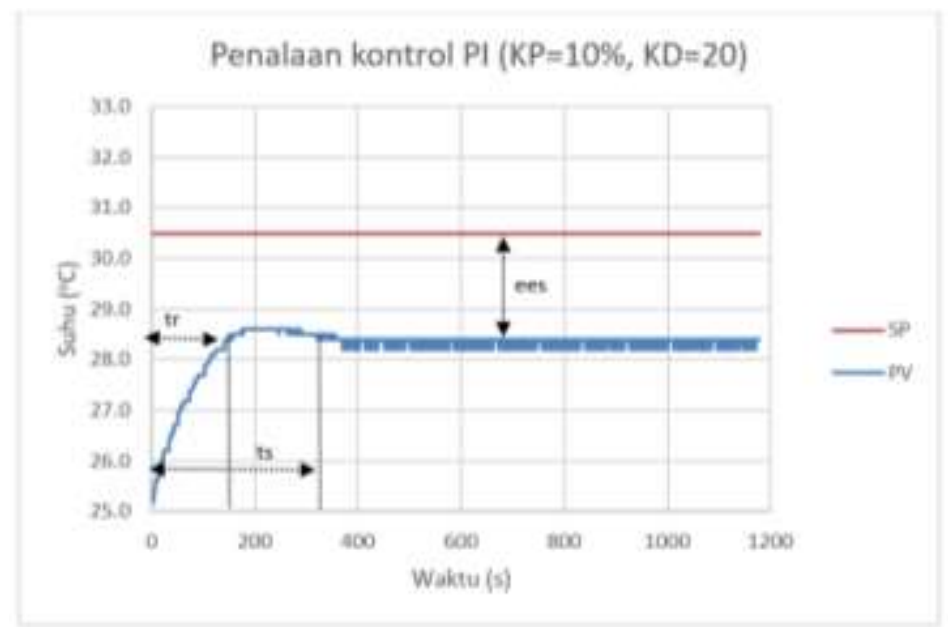

Gambar 9. Grafik Penalaan Manual PID $\left(K p=10 \%, K_{D}=20\right)$ 
Penalaan PD secara manual pada pengujian ketiga menghasilkan tanggapan sistem dengan $\operatorname{tr}=142$ detik, begitu juga dengan waktu tunak (settling time) juga memiliki nilai yaitu ts $=142$ detik. Tanggapan sistem ini juga menghasilkan ess (error steady state) sebesar $2.1^{\circ} \mathrm{C}$ dari nilai set point (SP).

\subsubsection{Pengujian Kontrol PD ( $\left.K_{P}=10 \%, K_{I}=100, K_{D}=20\right)$}

Pengujian kontrol PID pada pengujian ini dilakukan dengan memberikan nilai $\mathrm{Kp}=10 \%$, $K_{I}=100$, dan $K_{D}=20$ serta nilai Set Point $(S P)=30.5^{\circ} \mathrm{C}$, berikut ini adalah Gambar 10 yang menunjukkan grafik kontrol PID.

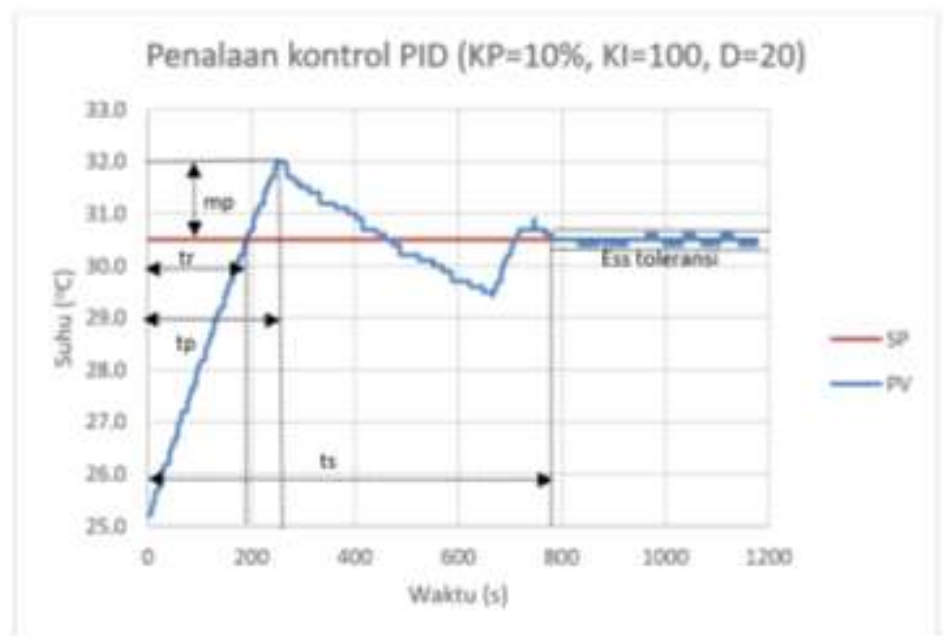

Gambar 10. Grafik penalaan manual PID $(K p=10 \%, K I=100, K D=20)$

Penalaan PID secara manual pada pengujian ketiga menghasilkan tanggapan sistem dengan $\mathrm{tr}=190$ detik, waktu puncak (peak time) $\mathrm{tp}=250$ detik, serta waktu tunak (settling time) ts=703 detik. Tanggapan sistem ini juga menghasilkan maximum over shoot (mp) sebesar 1.5 ${ }^{\circ} \mathrm{C}$ dari nilai set point (SP).

\subsection{Penalaan PID Secara Otomatis (Autotuning) $\mathrm{SP}=33.4^{\circ} \mathrm{C}$}

Proses penaalaan secara autotuning pada pengujian ketiga dilakukan dengan mengaktifkan mode autotuning serta memberikan nilai (Set Point) $\mathrm{SP}=33.4^{\circ} \mathrm{C}$ dan sampling $=0.5 \mathrm{~s}$. Hasil penalaan membutuhkan waktu selama 345 detik, hingga nilai PID menghasilkan nilai $\mathrm{KP}=0.1 \%, \mathrm{~K}=58$, dan $\mathrm{KD}=7$. Berikut ini adalah Gambar 11 yang menunjukkan hasil penalaan ulang pada $\mathrm{SP}=33.4^{\circ} \mathrm{C}$.

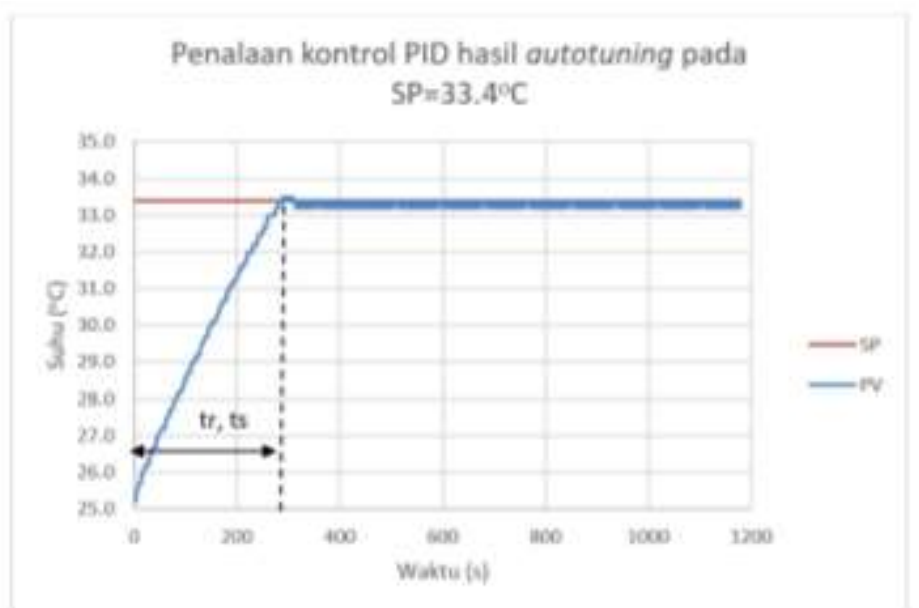

Gambar 11. Penalaan PID hasil autotuning, $\mathrm{SP}=33.4^{\circ} \mathrm{C}(\mathrm{KP}=0.1 \%, \mathrm{KI}=58$, dan $\mathrm{KD}=8)$ 
Pengujian terhadap parameter PID yang dihasilkan secara autotuning pada $\mathrm{SP}=33.4^{\circ} \mathrm{C}$, menghasil respon sistem dengan kecepatan waktu naik (rise time) dan waktu tunak (settling time) sebesar 322 detik. Pengontrolan ini tidak menghasil nilai melampaui batas acuan (maximum overshoot) serta gangguan keadaan tunak (error steady state) yang kecil, sehingga menghasilkan keadaan yang stabil sesuai dengan nilai acuan pada SP (Set Point).

\subsection{Pemodelan Sistem Menggunakan Matlab}

Pemodelan sistem dilakukan dengan menggunakan sistem indefitikasi pada matlab, data output yang diperoleh dari PLC berupa excel harus terlebih dahulu didefinisikan variabelnya menggunakan perintah "iddata(variabel keluaran, masukan, sampel waktu)", setelah itu membuka identification system tools pada bagian menu APPS, selanjutnya menambahkan variabel yang telah dibuat kemudian melakukan estimate untuk melihat pemodelan sistemnya. Gambar 12 ini adalah hasil pemodelan sistem .

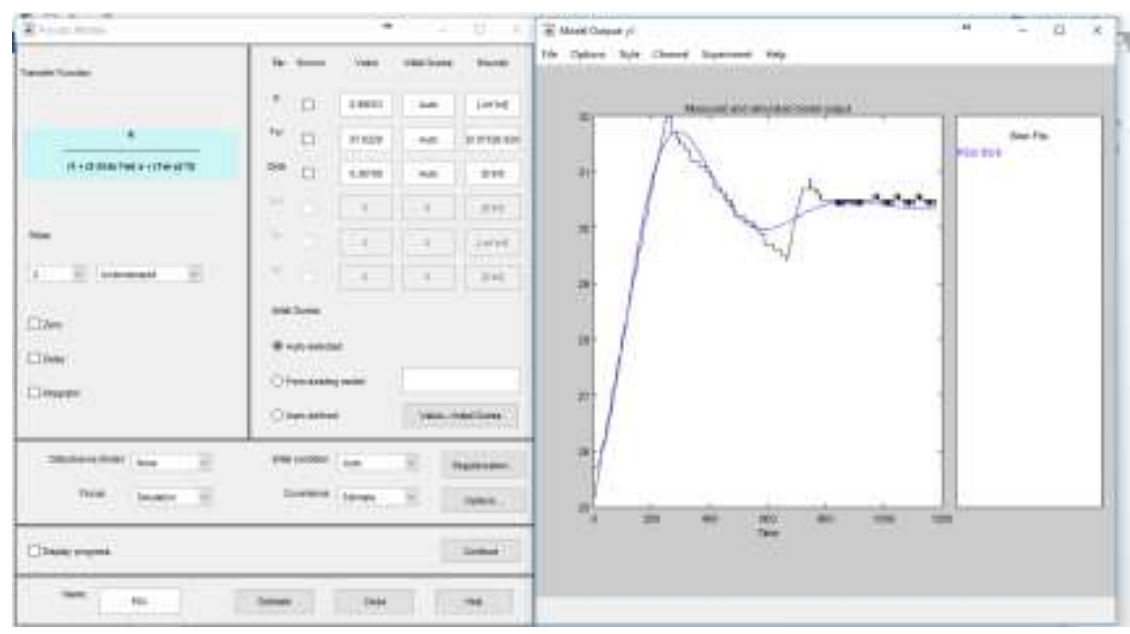

Gambar 12. Pemodelan sistem menggunakan matlab

Pemodelan sistem yang diujikan diambil dari data pengujian PID yang telah diujikan dengan pengaturan parameter PID $\left(\mathrm{Kp}=10 \%, \mathrm{~K}=100, \mathrm{~K}_{\mathrm{D}}=20\right)$, Gambar 13 adalah identifikasi pada matlab.

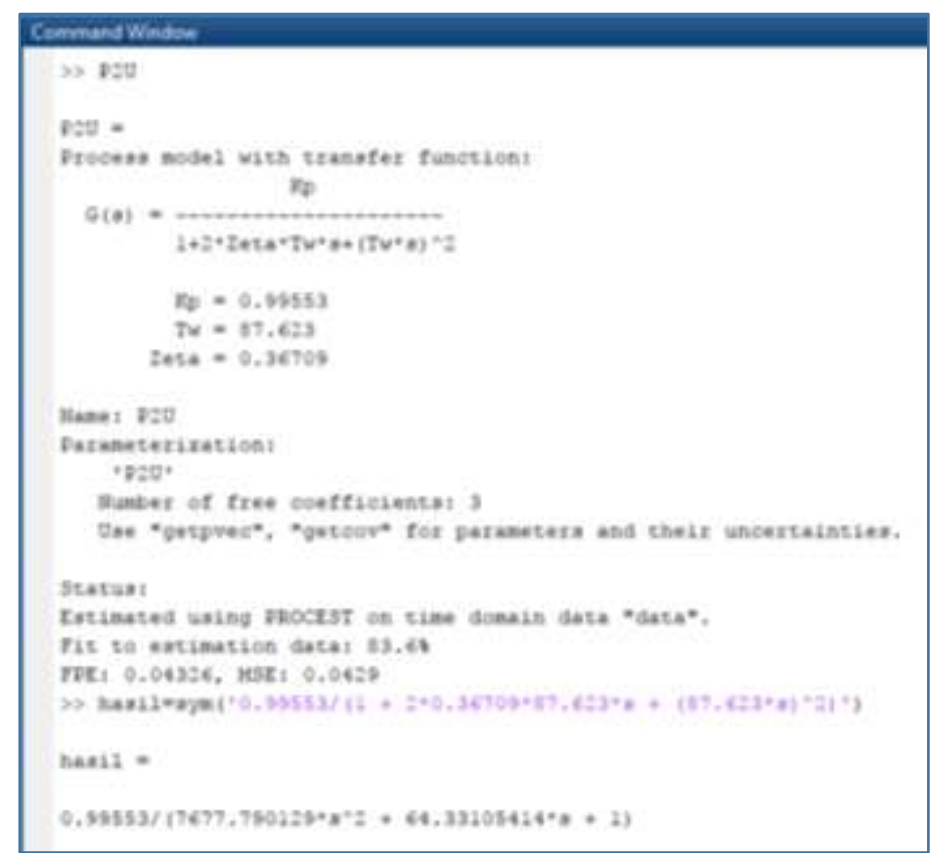

Gambar 13. Fungsi alih dari hasil estimasi matlab 
Fungsi yang telah diperoleh selanjutnya diolah kembali dengan memasukkan parameter yang telah didapat yaitu parameter $\mathrm{Kp}=0.99553$, $\mathrm{Tw}=87.623$, dan Zeta $=0.36709$. Sehingga persamaan fungsi alih dari pemodelan sistem :

$$
\begin{gathered}
G(s)=\frac{\mathrm{Kp}}{1+2 \cdot \text { Zeta } \cdot \mathrm{Tw} \cdot \mathrm{s}^{2}+(\mathrm{Tw} \cdot \mathrm{s})^{2}} \\
G(s)=\frac{0.99553}{7677.790129 \mathrm{~s}^{2}+64.33105414 \mathrm{~s}+1}
\end{gathered}
$$

Persamaan pemodelan yang telah didapatkan, menunjukkan bahwa fungsi alih yang diperoleh merupakan sistem dengan orde 2 , hal ini dapat dilihat dari pangkat tertinggi pada variabel (s), yaitu 2 .

\section{Kesimpulan}

Berdasarkan hasil penelitian dan pembahasan yang telah dilakukan mengenai sistem pengontrol suhu ruangan dengan algoritma PID menggunakan PLC OMRON CP1E-NA20DR-A, penelitian ini telah berhasil merancang purwarupa dan mengaplikasikan kontrol suhu ruangan dengan menggunakan PLC OMRON CP1E-NA20DR-A, penelitian ini juga telah berhasil menerapkan fungsi kontrol PID otomatis (autotuning) dan kontrol PID manual yang dapat di kontrol langsung pada tampilan antarmuka pengontrol suhu ruangan. Berdasarkan hasil pengujian, pada nilai setpoint antara $25^{\circ} \mathrm{C}-35^{\circ} \mathrm{C}$ respon sistem akan bekerja dengan baik pada nilai kostanta Proportional $0,1 \%$, Integral $=52$, dan Derivative $=7$, pada pengaturan ini menghasilkan respon sistem yang cepat dalam mencapai kestabilan dan nilai overshoot yang kecil (overshoot $=0$ ).

\section{Referensi}

[1] Bueche, F.J \& Hecht, E. (2006). Schaum's Outlines Teori dan Soal-soal Fisika Universitas Edisi Kesepuluh. Jakarta: Erlangga.

[2] National Semiconductor. (n.d.). Datasheet LM35DZ Precision Centigrade Temperature Sensors.

[3] OMRON. (2009). CP1E Cost-effective CP1E with Enhanced Expandability for Analog and Temperature Control. Japan: OMRON Corporation.

[4] OMRON. (2014). CP1E CPU Unit Instructions Reference Manual. Printed in Japan: OMRON Corporation.

[5] OMRON. (n.d). Solid State Relay (SSR) G3MB. Diperoleh dari http://www.omronrussia.com/doc/relay/ssr/g3mb.pdf. (diakses pada 22 Mei 2017).

[6] OMRON. (n.d). CX-ONE Introduction Guide. Japan: OMRON Corporation

[7] OMRON. (n.d). CX-Programmer Introduction Guide. Japan: OMRON Corporation

[8] Rawung, A. E. (2013). Perekayasaan Sistem Kontrol. Jakarta: Kementrian Pendidikan \& Kebudayaan. 